\title{
First Documented Attack on a Live Human by a Cookiecutter Shark (Squaliformes, Dalatiidae: Isistius sp.) ${ }^{1}$
}

\author{
Randy Honebrink, ${ }^{2,6}$ Robert Buch, ${ }^{3,4}$ Peter Galpin, ${ }^{5}$ and George H. Burgess ${ }^{3}$
}

\begin{abstract}
An adult long-distance swimmer attempting to cross the 'Alenuihāhā Channel between the Hawaiian islands of Hawai' $i$ and Maui was twice bitten by a cookiecutter shark (Squaliformes, Dalatiidae, Isistius sp.). One of these bites presented as an open, round, concave wound typically observed in cookiecutter shark bites inflicted by members of this genus on a broad spectrum of large biota such as marine mammals, elasmobranchs, and bony fishes. The open wound was debrided, subjected to negative pressure wound therapy, and a split thickness skin graft harvested from the left thigh. Postoperative recovery was complicated by delayed healing of the inferior portion of the graft, and cultures and biopsy were normal skin flora and normal tissue, respectively. At 6 months after the incident, the area appeared to be healing with a stable eschar, and by 9 months the wound was healed. Humans entering pelagic waters at twilight and nighttime hours in areas of Isistius sp. occurrence should do so knowing that cookiecutter sharks are a potential danger, particularly during periods of strong moonlight, in areas of man-made illumination, or in the presence of bioluminescent organisms.
\end{abstract}

The Two SPECIES of cookiecutter sharks of the dalatiid genus Isistius, I. brasiliensis Quoy \& Gaimard, 1824, and I. plutodus Garrick \& Springer, 1964, are small pelagic sharks best known for their feeding behavior, which has been characterized by some authors as ectoparasitic. Cookiecutter sharks use specialized pharyngeal muscles, upper jaw, hyoid and branchial arches, and fleshy lips to suck onto prey, inserting hooklike upper teeth and pro-

\footnotetext{
${ }^{1}$ Manuscript accepted 29 August 2010.

${ }^{2}$ Hawai'i Division of Aquatic Resources, 1151 Punchbowl Street, Honolulu, Hawai'i 96813.

${ }^{3}$ International Shark Attack File, Florida Program for Shark Research, Florida Museum of Natural History, University of Florida, Gainesville, Florida 32611.

${ }^{4}$ NOAA Fisheries Service, Northeast Regional Office (NERO), Gloucester, Massachusetts 01930.

${ }^{5}$ Maui Memorial Medical Center, 221 Mahalani Street, Wailuku, Hawai'i 96793.

${ }^{6}$ Corresponding author (e-mail: randy.r.honebrink@ hawaii.gov).
}

Pacific Science (2011), vol. 65, no. 3:365-374 doi: $10.2984 / 65.3 .365$

(C) 2011 by University of Hawai'i Press

All rights reserved portionately massive lower teeth into the prey, then may twist in a circular motion to remove a plug of flesh (Shirai and Nakaya 1992, Motta and Wilga 2001, Lowry et al. 2009). The resultant circular and concave wounds have been observed on the bodies of a variety of large pelagic species, including such diverse biota as cetaceans, pinnipeds, scombroid fishes (tunas, snake mackerels, billfishes), sharks and rays, and sea turtles (Jones 1971, Papastamatiou et al. 2010). It is likely that almost any large epipelagic or mesopelagic species is fair game for cookiecutter sharks.

There have been scattered reports of cookiecutter shark interactions with people, but all implicated incidents have involved bites on deceased humans. These are characterized as "scavenges" by the International Shark Attack File (ISAF), which investigates and analyzes shark-human interactions, as opposed to allocation to the "unprovoked" or "provoked" shark attack categories, which by definition involve bites on live human victims. In this paper we provide the first documentation of an attack by a cookiecutter shark on a live human, an unprovoked attack that occurred in waters of Hawai'i. 
MATERIALS AND METHODS

Specifics and description of the incident were obtained from the victim directly through a telephone interview 7 days after the incident, a follow-up face-to-face interview 4 days later, and subsequent e-mail correspondence. The victim also completed the International Shark Attack File's standard Abbreviated Shark Attack Questionnaire.

The victim's operating room treating physician, the third author of this communication (P.G.), spoke with the victim throughout the course of treatment and, with the victim's permission, shared relevant information with the other authors as this collaboration developed. The wounds were observed firsthand by P.G., who provided all surgical and postoperative follow-up treatment. Photos of the wounds were taken by the physician and the victim, and are archived in the International Shark Attack File at the Florida Museum of Natural History, University of Florida, Gainesville.

Sea-surface temperature and Global Positioning System (GPS) coordinates were obtained by instrumentation aboard the Radon escort vessel. Sun and moon data were obtained from the U.S. Naval Observatory Web site (http://www.usno.navy.mil/ USNO). Tidal data were obtained from the NOAA tides and currents Web site (http:// tidesandcurrents.noaa.gov). Water depth was estimated from U.S. National Ocean Service (NOS) chart 19320. Other weather and water conditions, and time of the incident, were recalled by the victim. Photos of Isistius-bitten fishes were taken at United Fishing Agency, Honolulu, on 8 December 2009.

\section{RESULTS}

\section{Specifics of the Incident}

Date: 16 March 2009.

Time: 2003 hours, $90 \mathrm{~min}$ after the 1833 hours sunset and $68 \mathrm{~min}$ after the 1855 hours civil twilight.

Location: $16 \mathrm{~km} \mathrm{NW}$ of 'Upolu Point, Hawai'i Island. GPS coordinates approximately $20^{\circ} 23^{\prime} 17.4^{\prime \prime} \mathrm{N}, 155^{\circ} 57^{\prime} 27^{\prime \prime} \mathrm{W}$.
Depth of water: Surface over water depths of approximately $359 \mathrm{~m}$.

Weather conditions: Winds light and variable, clear skies, ambient starlight, no moon.

Water conditions: Sea calm, tide slack high, water clear, sea-surface temperature $22.5^{\circ} \mathrm{C}$.

Victim: Caucasian male, $61 \mathrm{yr}$ old, height $178 \mathrm{~cm}$, weight $91 \mathrm{~kg}$.

Victim activity: Swimming.

Victim clothing: Swim trunks; no rash guard, watch, or jewelry.

\section{Description of the Incident}

The victim was an accomplished longdistance swimmer attempting to cross the 'Alenuihāhā Channel on a straight-line track from 'Upolu Point on the island of Hawai' $i$ to Kaupō, Maui (Figure 1). The total distance was $47.5 \mathrm{~km}$, and crossing time was expected to take 16-20 hr. A GPS unit aboard the escort vessel, a $9.1 \mathrm{~m}$ (30 ft) Radon, was used for navigation. In addition to the Radon, a oneperson kayak was used in support of the swimmer.

Departure from the 'Upolu Point coastline occurred at 1530 hours during a rising tide, to take advantage of tide and current conditions. The kayak remained about $1 \mathrm{~m}$ to the right of the victim. The Radon maintained a distance of 50-120 m ahead of the kayak. Every half hour the boats stopped, and the victim swam to the kayak to consume an "endurance fuel." The two boats communicated with each other by VHF radio at those times.

About 10 min after sunset the Radon's captain illuminated stern deck lights to maintain visual contact with the kayak. During the next regular stop at 1900 hours the captain indicated by radio that he saw squid (probably Sthenoteuthis oualaniensis) attracted to the lights. The victim, who was already aware of the presence of jellyfish and other macroplankton, did not notice any difference in marine life after the Radon's stern lights were turned on. At approximately the same time, the kayaker illuminated a glow stick and placed it on the kayak's deck, less than $30 \mathrm{~cm}$ above the water. However, the glow stick did not cast any light directly into the water due to the shape of the deck. 


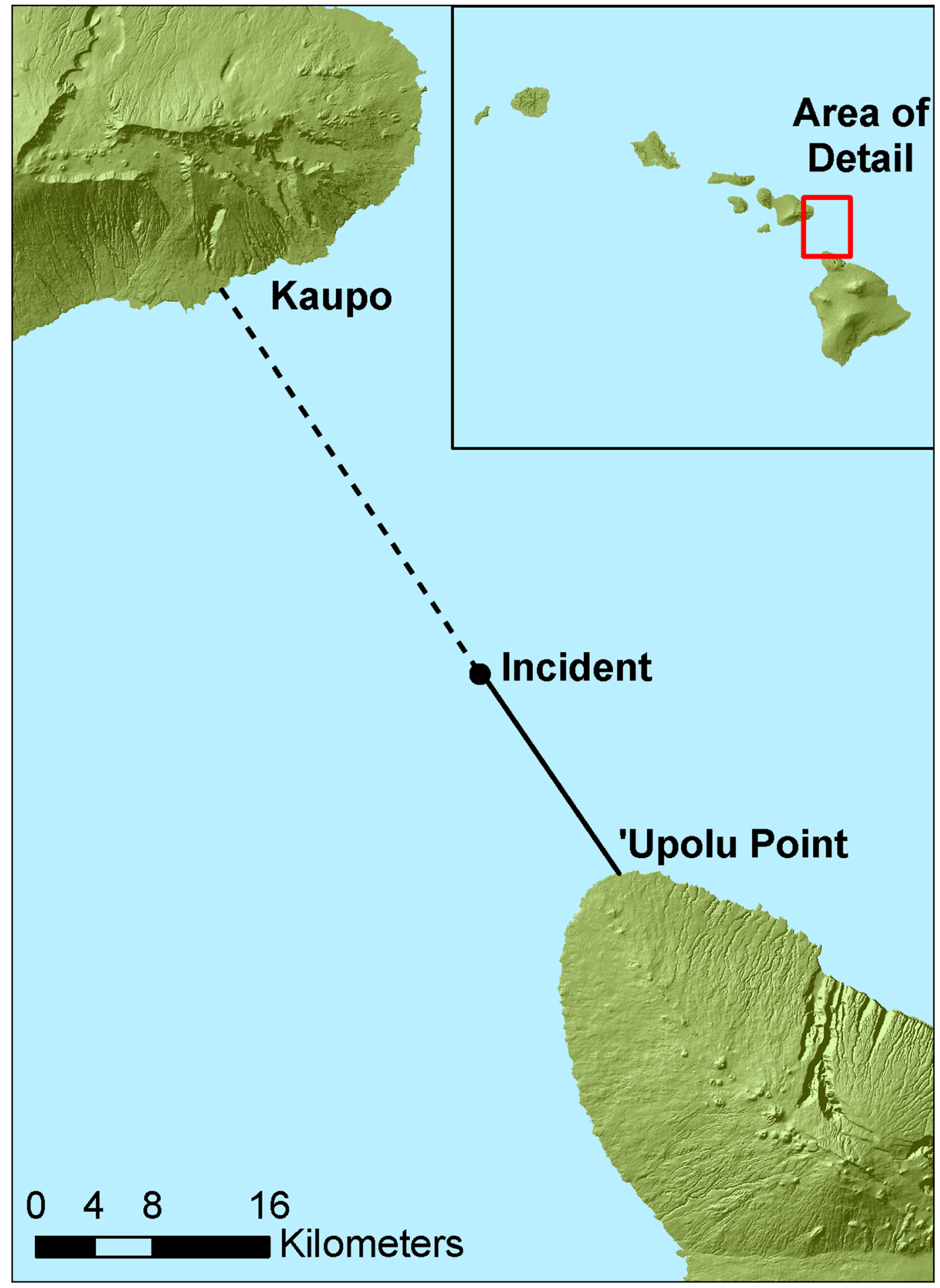

FIGURE 1. Intended track of channel crossing and location of incident. 

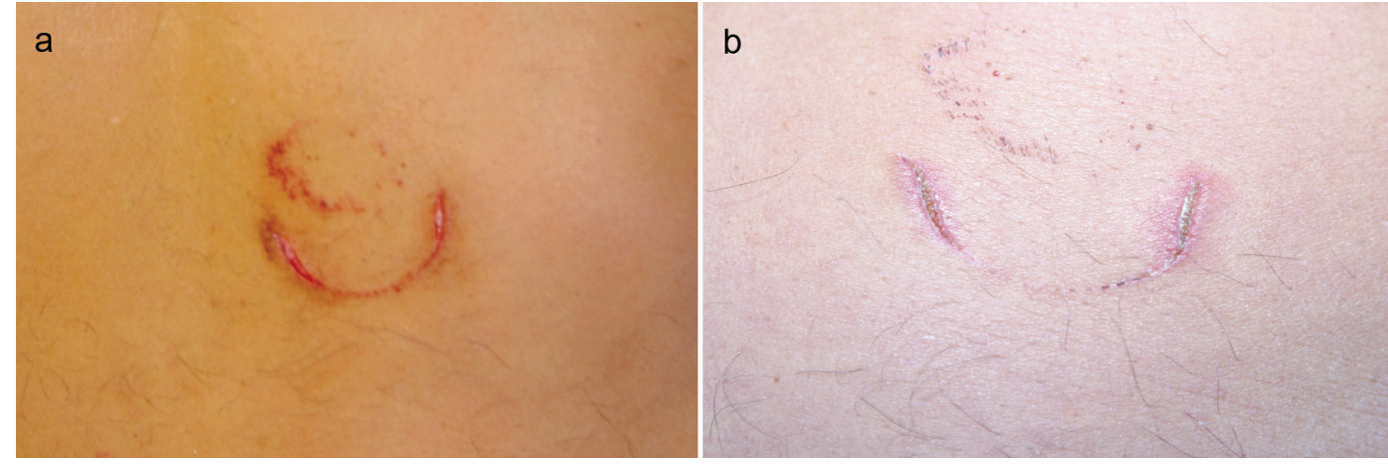

Figure 2. Wound to victim's sternum: $a$, in emergency room; $b$, at 7 days.

Four hours into the swim (1930 hours), during a regular stop, the captain of the Radon indicated that he was having a hard time seeing the kayak and asked the kayaker to turn on his secondary light. The victim turned on the unit, which was mounted over the kayak's bow in a manner that caused its red and green light to shine directly into the water. About 10 min after the kayak's bow light was turned on, the victim was bumped by a squid. Over the next $20 \mathrm{~min}$ he was bumped by squid two or three more times in the shoulder and side areas at irregular intervals.

At 2003 hours, the victim suddenly felt a very sharp pain on his lower chest and assumed it was a triggerfish bite. The sensation was instantaneous and localized, like a pinprick, and felt like a bite from a very small mouth. The victim yelped and swam over to the kayak, turned off the bow light, and was in the process of getting into the kayak with his legs vertical and "egg-beatering" to maintain position when he felt something bite his left calf. The time interval between the two bites was less than $15 \mathrm{sec}$. The sensation of the bite to the leg was slightly more prolonged (but still very quick, less than a second), involved some pressure, and was less painful than the chest bite.

The victim was retrieved by the escort vessel, from which he called his physician. He was advised to control bleeding through elevation and direct pressure until reaching shore. After docking, about 2 hr later, he was transported to Maui Memorial Medical Center in Wailuku.

\section{Description and Treatment of Wounds Received}

Inspection of the wounds in the emergency room showed a superficial C-shaped wound approximately $5 \mathrm{~cm}$ in diameter on the mid/ lower sternum (Figure 2) and a circular open wound of the posterior lower left leg (Figure $3)$. The leg wound was located at the junction of the middle and lower one-third of the calf. It represented a near circle and measured approximately $10 \mathrm{~cm}$ in diameter and $4 \mathrm{~cm}$ in depth. The wound went through the investing fascia of the gastrocnemius muscle and removed a core of tissue, including portions of the gastrocnemius and the superior margin of the Achilles tendon.

The patient was taken to the operating room that night, where debridement was performed. Negative pressure wound therapy (Wound V.A.C.) was begun on the patient. A second debridement was performed $48 \mathrm{hr}$ after the injury. Wound closure was obtained on postinjury day 14 with a split thickness skin graft (Figure 4) harvested from the left thigh.

Postoperative recovery was complicated by delayed healing of the inferior portion of the graft (approximately $5 \%-10 \%$ of the graft surface, corresponding to the location of the Achilles tendon margin). Subsequent cultures and biopsy showed normal skin flora and nor- 


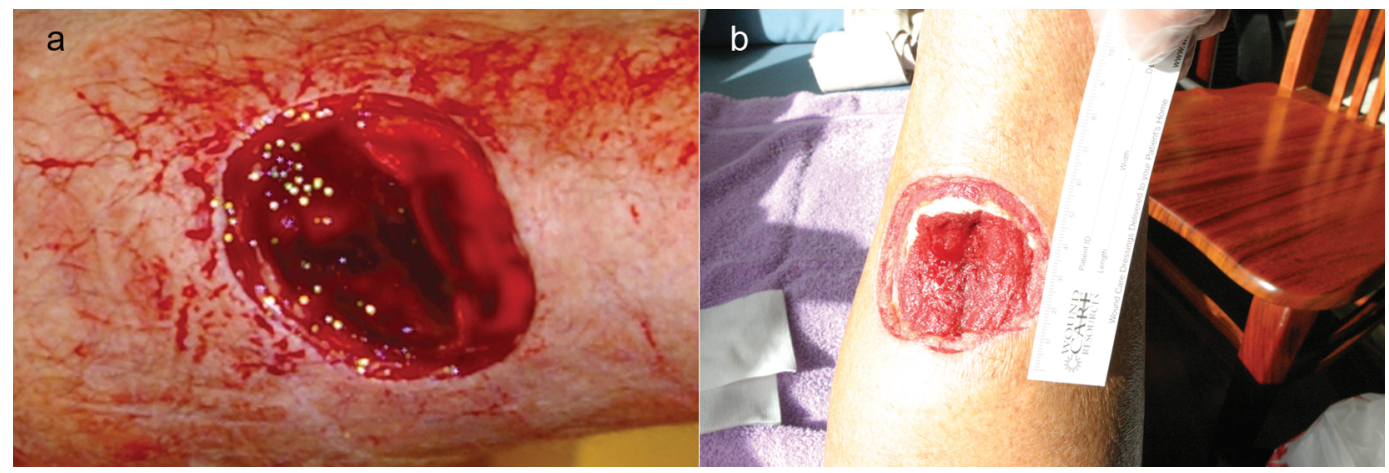

FIGURE 3. Wound to victim's leg: $a$, in emergency room; $b$, at 7 days.

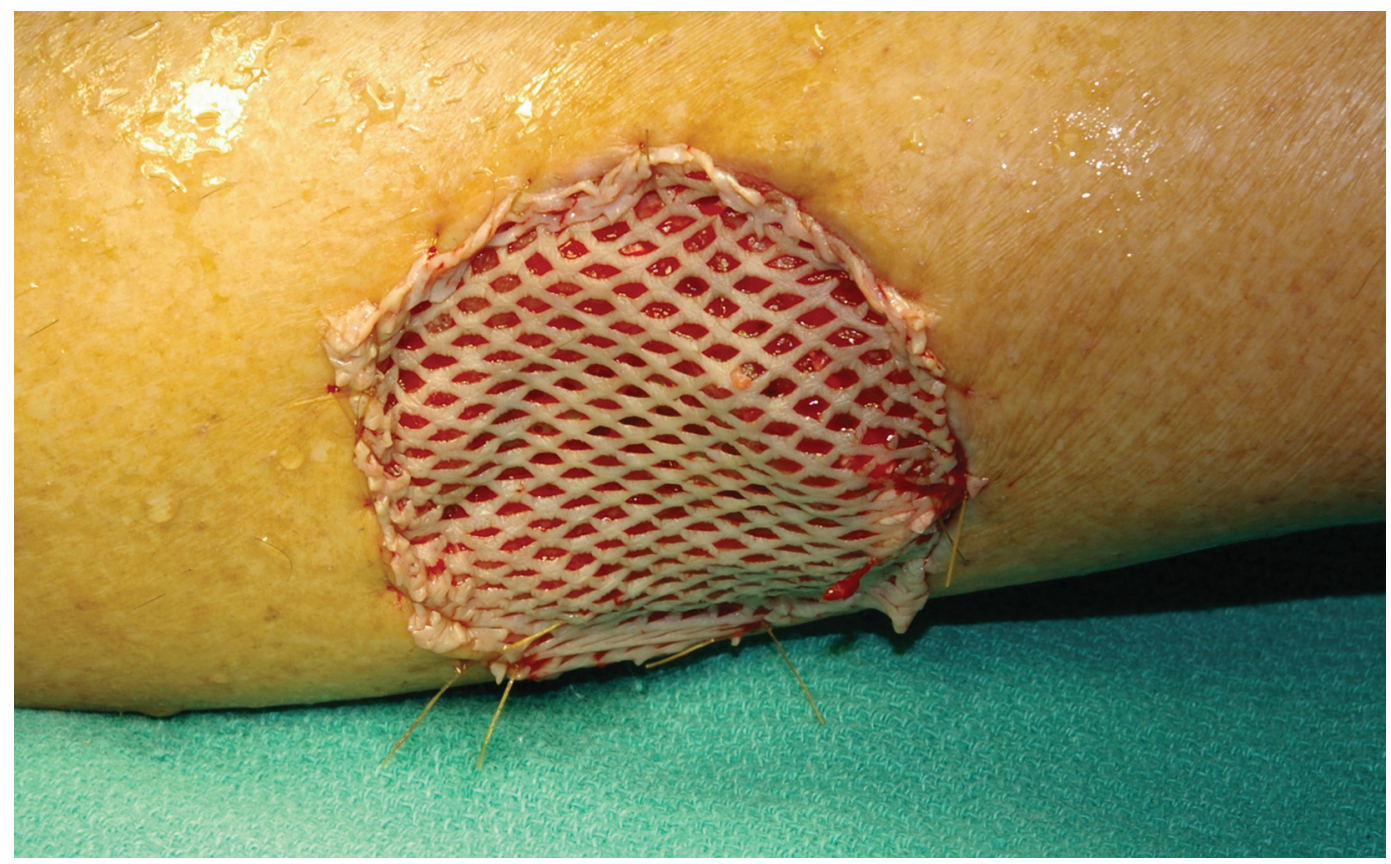

Figure 4. Skin graft on victim's leg at 14 days.

mal tissue, respectively. At 6 months after the incident, the area appeared to be healing with a stable eschar. By 9 months, the wound was essentially healed (Figure 5).

\section{Identification of the Shark}

The appearance of the wounds allowed immediate recognition of them as the bites of a cookiecutter shark (Isistius sp.). The circumstances surrounding the incident, specifically habitat, depth, and time of day, fit the behavior pattern of Isistius, which migrates vertically to surface waters at night to feed (Last and Stevens 1994, Papastamatiou et al. 2010). Because I. brasiliensis is the only species of the genus documented as occurring in Hawaiian waters (Mundy 2005), it is likely that this 


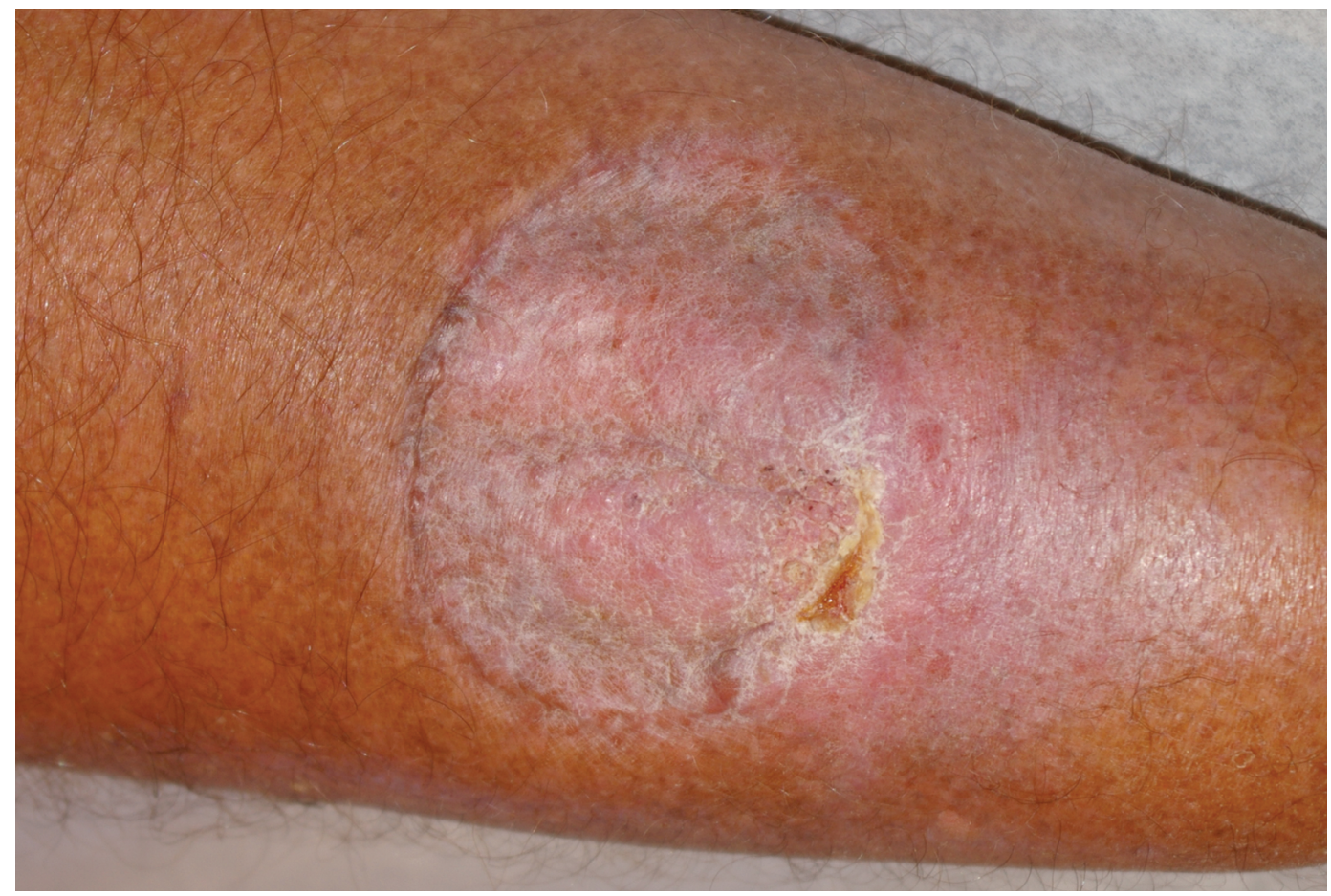

Figure 5. Healed leg wound at 9 months.

species was involved in the incident. In addition, the distances between mandibular tooth apices, as evidenced by the puncture wounds on the victim's sternum, were more consistent with I. brasiliensis than I. plutodus (Compagno 1984).

Small round or oval scooped-out wounds on fishes and cetaceans have been reported in the literature as early as 1886, and reports through 1969 were summarized by Jones (1971). The cause of these wounds had been attributed to bacteria, invertebrate parasites, or lampreys (e.g., Pike 1951). Jones (1971) presented persuasive evidence that crater and crescentic wounds, and related scars, found on large pelagic fishes and cetaceans were the result of bites inflicted by I. brasiliensis (Figure 6).

In addition to the fishes and cetaceans summarized by Jones (1971), Isistius bites have also been documented on many other species, including the whale shark, Rhincodon typus (Fitzpatrick et al. 2006); megamouth shark,
Megachasma pelagios (Taylor et al. 1983); killer whale, Orcinus orca (Visser 1999, Baird et al. 2006, Burdin et al. 2007, Renner and Bell 2007); and pinnipeds including the leopard seal, Hydrurga leptonyx (van den Hoff et al. 2005); northern elephant seal, Mirounga angustirostris (Le Boeuf et al. 1987); subantarctic fur seal, Arctocephalus tropicalis (Velozo et al. 2008, Souto et al. 2009); and Hawaiian monk seal, Monachus schauinslandi (Reddy and Griffith 1988, Bertilsson-Friedman 2005).

The general description of those wounds is consistent with the appearance of the leg wound in this case. In addition, the wound in the sternum region (Figure 2) exhibited two C-shaped arcs of small, shallow puncture wounds consistent with the mandibular teeth of I. brasiliensis (Figure 7). These wounds may have been caused by two rapidly successive attempts to bite, one a bit more successful than the other, likely thwarted by the proximity of the underlying thoracic skeleton and relative lack of soft tissue, flattened nature of the vic- 


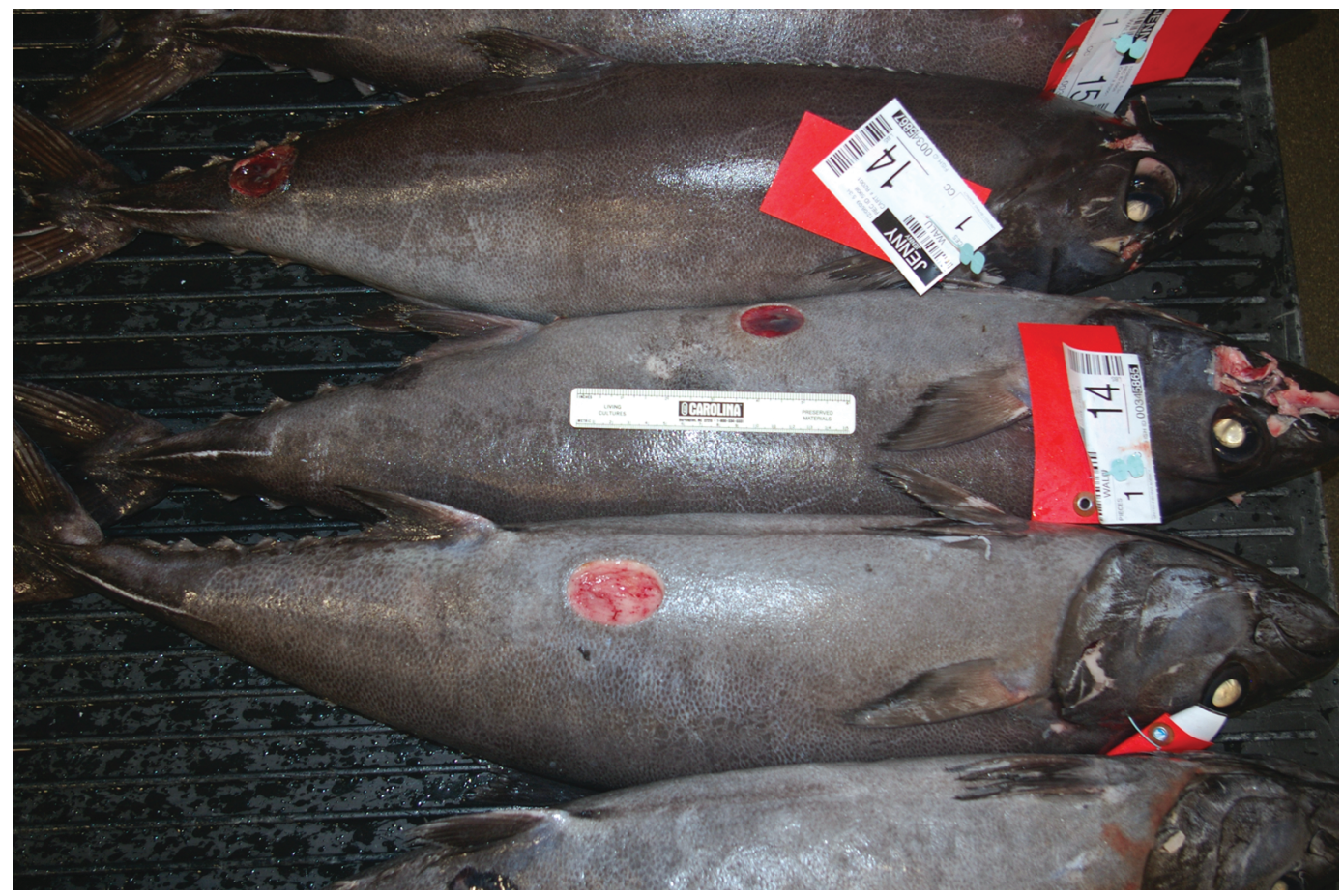

Figure 6. Crater wounds observed on oilfish, Ruvettus pretiosus, at Honolulu fish auction.

tim's body at that location, and awkward attack angle (near vertical) taken by the shark. By contrast, the subsequent predatory event on the victim's leg benefited from a more favorable angle of attack and robust availability of soft tissue, resulting in a successfully completed circular and concave bite.

The behavioral mechanism by which Isistius scoops out a plug of flesh from its host has been hypothesized but not observed. It is believed to attach itself by means of suctorial lips and a modified pharynx, then twist (Compagno 1984) or spin (Last and Stevens 1994) as it drives its lower teeth into its victim. Jahn and Haedrich (1987) provided evidence that the bite can be "accomplished by a single motion of the lower jaw" but did not dismiss the "melon-ball cutter model." In cases where crater wounds are elongate ovals, a single jaw motion would seem to be more consistent with the shape of the wound than would a twisting or spinning motion on the part of the shark. The victim in this case experienced a brief (less than $1 \mathrm{sec}$ ) sensation of pressure during infliction of the leg wound but no sense of any sort of twisting motion. Close inspection of wound photographs does not provide evidence that indicates whether the shark's bite involved such movement.

\section{Estimation of Size of the Shark}

Papastamatiou et al. (2010) utilized a mouth width to total length regression to estimate sizes of cookiecutter sharks that inflicted bites on several commercial fish species. However, the variability in wound size estimates and measurements in this case makes it unusable. Initial estimate of the leg wound size was 10 $\mathrm{cm}$ in diameter. Measurements taken 7 days after the injury provided dimensions of $5 \mathrm{~cm}$ by $6.5 \mathrm{~cm}$, but by that time the size of the wound was somewhat reduced because healing was taking place.

Jones (1971) indicated that the largest dimensions reported for oval crater wounds 


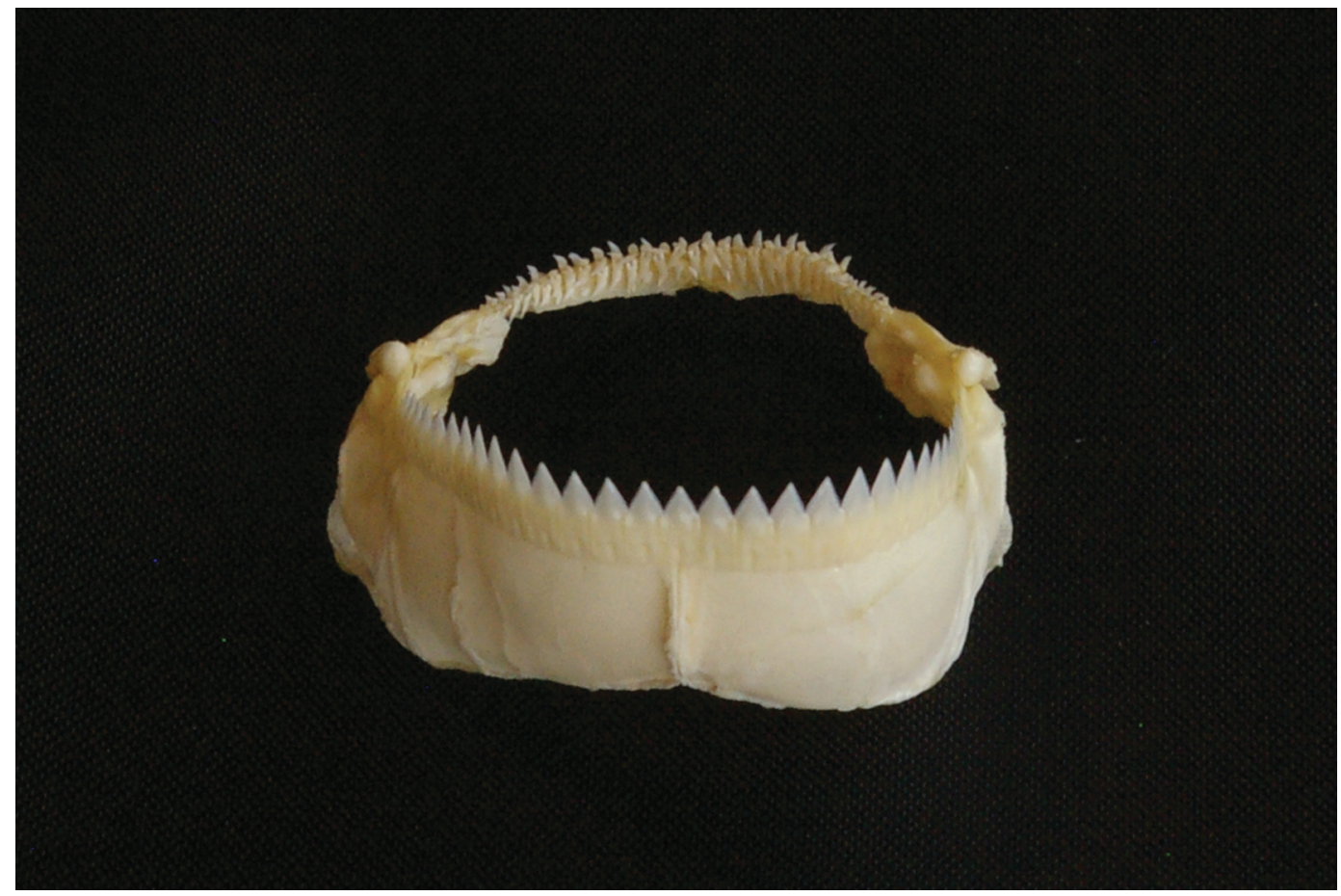

Figure 7. Jaws of Isistius brasiliensis.

caused by Isistius were 4 or $5 \mathrm{~cm}$ by $7 \mathrm{~cm}$. It is not known on what type of animal(s) these wounds were observed, nor the degree of healing that had already taken place. The maximum length attained by $I$. brasiliensis is reported to be $50 \mathrm{~cm}$ (Compagno 1984). The size of the victim's leg wound is comparable with the largest reported bite dimensions for this species, indicating an individual that was certainly an adult and likely near the maximum size usually encountered (about $40 \mathrm{~cm}$ ).

\section{Comparison with Other Recorded Incidents}

Jahn and Haedrich (1987) indicated that Isistius swims in schools and may pose a threat to divers in tropical waters. They "were recently told of an underwater photographer" who had been "attacked by a swarm of small $(<3 \mathrm{ft})$ sharks, and who had the scars to prove it." They also referenced a 1955 report of a shipwrecked crew in the mid-Atlantic, just north of the equator, who "were greatly bothered by the attacks of an extremely ferocious small fish less than a foot long and blunt-nosed ... These small fish swam in schools and were very persistent ... The bites were clean-cut and upwards of an inch or more deep." However, neither of these incidents was reported to the ISAF, and although they may have implicated Isistius, there is insufficient documentation to positively confirm cookiecutter shark involvement. Anecdotal reports of Isistius bites on people in Hawaiian waters have been made (M. Parry, NOAA Fisheries Honolulu, pers. comm.), but they are rare and undocumented.

The ISAF database includes only two other incidents involving Isistius bites. In both cases the bites were judged to have occurred postmortem. A 1992 case (ISAF 1860), also from Hawai' $i$, involved a 70-yr-old man who was discovered floating on his back, tied to an ice chest, 1 day after being reported missing from a fishing trip. The medical examiner's report 
(Gunatilake 1992) officially attributed the death to asphyxia by drowning. According to the report, evidence of injury included "two circular, punched-out, postmortem lesions ... measuring $5.0 \times 5.0 \mathrm{~cm}$ and $1.5 \mathrm{~cm}$ in depth. These lesions are located side by side. They appear to extend through the subcutaneous tissue to the muscles." Additional curvilinear lacerations measuring $3.0 \mathrm{~cm}$ in diameter were also present. The report states, "the above lesions are consistent with 'Cookiecutter' shark bites.”

A second case (ISAF 4657) of postmortem scavenging by Isistius was reported by Makino et al. (2004) and Ihama et al. (2009). The body of a suicidal 60 -yr-old woman missing for 6 days was recovered bearing multiple Isistius bites. Injuries were typical of those observed on nonhuman subjects: "The body had several almost perfectly circular injuries and Cshaped incision injuries with almost circular flaps of skin" (Makino et al. 2004). Bites were $3-8 \mathrm{~cm}$ in diameter. These were attributed to cookiecutter sharks of the Isistius genus (I. brasiliensis and/or I. plutodus).

\section{DISCUSSION}

Isistius brasiliensis migrates to surface waters at night, and by day to depths of at least 1,000 m (Last and Stevens 1994). Aside from its unique "hit and run" feeding behavior on large prey items, it also consumes free-living prey, including squid (Compagno 1984). The purpleback squid, Sthenoteuthis oualaniensis, feeds on other cephalopods and midwater fishes, particularly diurnally migratory myctophids (Parry 2006). Illumination of water at night by strong moonlight or man-made light sources may lead to feeding opportunities and attraction of myctophids and other oceanic bioluminescent organisms. Aggregations of $S$. oualaniensis are often seen at night near boats where the water is illuminated, and they are commonly caught in waters around the main Hawaiian Islands at night by jigging while shining lights into the water for the purpose of attraction (M. Parry, pers. comm.).

This incident took place in channel waters, well beyond the shallow coastal waters usually frequented by swimmers but in the natural nocturnal habitat of Isistius. Illumination of surface waters by the slow-moving escort vessel, and subsequently by the kayak, likely enhanced squid feeding activity and presented a feeding opportunity for Isistius. The squid were in such close proximity to the victim that he came in contact with them several times while swimming. The presence of a swimmer in this environment added a novel potential prey item for the opportunistic Isistius.

Humans entering pelagic waters during twilight and nighttime hours in areas of Isistius sp. zoogeographical ranges should do so with a full appreciation that cookiecutter sharks may consider a human an appropriate prey item, especially when near man-made illumination, during periods of bright moonlight, or in the presence of bioluminescent organisms.

\section{Literature Cited}

Baird, R. W., D. L. Webster, D.J.McSweeney, A. D. Ligon, G. S. Schorr, and J. Barlow. 2006. Diving behavior and ecology of $\mathrm{Cu}-$ vier's (Ziphius cavirostris) and Blainville's (Mesoplodon densirostris) beaked whales in Hawaii. Can. J. Zool. 84:1120-1128.

Bertilsson-Friedman, P. 2005. Distribution and frequencies of shark-inflicted injuries to the endangered Hawaiian monk seal (Monachus schauinslandi). J. Zool. 268:361368.

Burdin, A. M., E. Hoyt, O. A. Filatova, T. Ivkovich, K. Tarasyan, and H. Sato. 2007. Status of killer whales (Orcinus orca) in eastern Kamchatka (Russian Far East) based on photo-identification and acoustic studies. Preliminary results. International Whaling Commission Scientific Committee (SC/59/SM4).

Compagno, L. J. V. 1984. FAO species catalog. Vol. 4. Sharks of the world: An annotated and illustrated catalogue of shark species known to date. Part 1. Hexanchiformes to Lamniformes. FAO Fish. Synop. 125:93-95.

Fitzpatrick, B., M. Meekan, and A. Richards. 2006. Shark attacks on a whale shark (Rbin- 
codon typus) at Ningaloo Reef, Western Australia. Bull. Mar. Sci. 78:397-402.

Gunatilake, K. 1992. Autopsy report case no. 92-0650. Department of the Medical Examiner, City and County of Honolulu.

Ihama, Y., K. Ninomiya, M. Noguchi, C. Fuke, and T. Miyazaki. 2009. Characteristic features of injuries due to shark attacks: A review of 12 cases. Legal Med. (Tokyo) 11 (5): 219-225.

Jahn, A. E., and R. L. Haedrich. 1987. Notes on the pelagic squaloid shark Isistius brasiliensis. Biol. Oceanogr. 5:297-309.

Jones, E. C. 1971. Isistius brasiliensis, a squaloid shark, the probable cause of crater wounds on fishes and cetaceans. Fish. Bull. 69:791-798.

Last, P. R., and J. D. Stevens. 1994. Sharks and rays of Australia. Fisheries Research and Development Corporation. CSIRO, Australia.

Le Beouf, B. J., J. E. McCosker, and J. Hewitt. 1987. Crater wounds on northern elephant seals: The cookiecutter shark strikes again. Fish. Bull. 85:387-392.

Lowry, D., A. L. F. Castro, K. Mara, L. B. Whitenack, B. Delius, G. H. Burgess, and P. C. Motta. 2009. Determining shark size from forensic analysis of bite damage. Mar. Biol. (Berl.) 156:2483-2492.

Makino, Y., K. Tachihara, S. Ageda, T. Arao, C. Fuke, and T. Miyazaki. 2004. Peculiar circular and C-shaped injuries on a body from the sea. Am. J. Forensic Med. Pathol. 25:169-171.

Motta, P. J., and C. D. Wilga. 2001. Advances in the study of feeding behaviors, mechanisms, and mechanics of sharks. Environ. Biol. Fishes 60:131-156.

Mundy, B. C. 2005. Checklist of the fishes of the Hawaiian archipelago. Bishop Mus. Bull. Zool. 6.

Papastamatiou, Y. P., B. M. Wetherbee, J. O'Sullivan, G. D. Goodmanlowe, and C. G. Lowe. 2010. Foraging ecology of cookiecutter sharks (Isistius brasiliensis) on pelagic fishes in Hawaii, inferred from prey bite wounds. Environ. Biol. Fishes 88:361368.
Parry, M. 2006. Feeding behavior of two ommastrephid squids Ommastrephes bartramii and Sthenoteuthis oualaniensis off Hawaii. Mar. Ecol. Prog. Ser. 318:229-235.

Pike, G. C. 1951. Lamprey marks on whales. J. Fish. Res. Board Can. 8:275-280.

Reddy, M. L., and C. A. Griffith. 1988. Hawaiian monk seal population monitoring, pup captive maintenance program, and incidental observations of the green turtle at Kure Atoll, 1985. NOAA Tech. Mem. NMFS NOAA-TM-NMFS-SWFC-101.

Renner, M., and K. Bell. 2007. A white killer whale in the central Aleutians. Arctic 61:102-104.

Shirai, S., and K. Nakaya. 1992. Functional morphology of feeding apparatus of the cookie-cutter shark, Isistius brasiliensis (Elasmobranchii, Dalatiinae). Zool. Sci. (Tokyo) 9:811-821.

Souto, L. R. A., J. G. Abrão-Oliveira, R. Maia-Nogueira, and L. W. Dórea-Reis. 2009. Interactions between subantarctic fur seal (Arctocephalus tropicalis) and cookiecutter shark (Isistius plutodus) on the coast of Bahia, northeastern Brazil. Mar. Biodiv. Rec. 2:e123.

Taylor, L. R., L. J. V. Compagno, and P. J. Struhsaker. 1983. Megamouth: A new species, genus, and family of lamnoid shark (Megachasma pelagios, family Megachasmidae) from the Hawaiian Islands. Proc. Calif. Acad. Sci. 43:87-110.

van den Hoff, J., R. Fraccaro, P. Mitchell, I. Field, C. McMahon, H. Burton, W. Blanchard, P. Duignan, and T. Rogers. 2005. Estimating body mass and condition of leopard seals by allometrics. J. Wildl. Manage. 69:1015-1023.

Velozo, R. S., A. Schiavetti, and L. W. DóreaReis. 2008. Analysis of subantarctic fur seal (Arctocephalus tropicalis) records in Bahia and Sergipe, north-eastern Brazil. JMBA2 Biodiv. Rec. Ref. no. 6338 (http://www .mba.ac.uk/jmba/jmba2biodiversityrecords .php).

Visser, I. N. 1999. Antarctic orca in New Zealand waters? N. Z. J. Mar. Freshwater Res. 33:515-520. 